\title{
TRUST FORCE AND HOLE QUALITY OBSERVATION IN VARIOUS MAJOR PENETRATION ANGLE DRILLING OF CARBON FIBRE REINFORCED PLASTIC (CFRP)
}

\author{
M.F. JAAFAR \& M.S. SALLEH* \\ Faculty of Manufacturing Engineering, Universiti Teknikal Malaysia Melaka, Hang Tuah Jaya, 76100 Durian, Tunggal, \\ Melaka, Malaysia
}

\begin{abstract}
This paper has presented a new approach to study the comparison of thrust force and hole quality observation for three types of the drill with penetration angle of $0^{\circ}, 15^{\circ}$ and $30^{\circ}$ for drilling carbon fibre reinforced plastic (CFRP) laminates. The experimental approach is adapting to a combination of the design of experiment Taguchi's technique and analysis of variance (ANOVA). The drill types involved in the experiment are twist drill, dagger drill and straight flute drill. Plan of experiments adopted on the Taguchi technique with variable cutting parameters of drill types, drilling penetration angle, spindle speed and feed rate was performed in drilling autoclave carbon fibre reinforced plastic (CFRP) laminates. Based on the statistical experiment results, lower feed rate and lower penetration angle contribute lower thrust force at constant spindle speed operation for the twist, dagger and straight flute drill type based on response surface graph analysis in order of Taguchi design method. In term of hole quality observation, hole drilled with straight flute drill has the best hole quality compared with other drill types in this experiment. Drilling penetration angle contributes significant contribution to drilling thrust force and drilled hole quality.

KEYWORDS: CFRP, Drilling, Thrust Force
\end{abstract}

Received: Mar 30, 2020; Accepted: Apr 19, 2020; Published: Jul 17, 2020; Paper Id.: IJMPERDJUN2020367

\section{INTRODUCTION}

Advance and unique material are great options for many manufacturing industries. High technology industries like aerospace engineering, medical tools, automotive and marine parts required the materials that prestigious and lowcost besides its mechanical properties. Carbon fibre reinforced plastics (CFRP) are selective; the most suitable material has been chosen(Chawla, 2013). CFRP has unique characteristics, especially in the structure of the laminates material can provide such as high strength and stiffness properties and low-cost of maintenance (Breuer, 2016). Its strength-to-weight ratio is highly expedient compared to another high-performance material(Chung, 1994). Properties of fibre and the matrix, both fibre and matrix volume and fibre orientation influence the CFRP structure. Due to the difference in material properties, CFRP needs a strategised machining approach to obtain the best drilling results, especially in quality (Brinksmeier, Fangmann, \& Rentsch, 2011). CFRP's are an excellent option for materials for aerospace body construction due to its mechanical properties advantages (Zweben, 1981).

Depending on its applications on aircraft manufacturing application, super alloys commonly used for parts that required high-temperature section and CFRP commonly used for aero body section (Hafiz et al., 2017). The primary benefit of the material structure on fibre-reinforced materials lead to the machining of CFRP is dissimilar compared with metal alloys due to CFRP materials structure [7,8]. Drilling of CFRP has different divers action 
compared to metal drilling, and the defects also occurred dissimilar (Allen et al., 2017). CFRP machining such as drilling also can cause damages to composite laminates. The cutting and friction of two contacts between work part and tool drill bit are the resistance of drilling operations that withstand the penetration of the tool into work parts thus cause thrust force and torque (Caggiano, Angelone, \& Teti, 2017). The defects are matrix cracking, fibre pull-out, fibre fracture, fibre debonding (Soutis, 2005), delamination, fuzzing and spalling (Norberto Feito, Diaz-Álvarez, Cantero, Rodríguez-Millán, \& Miguélez, 2016). Delamination is the most common defect evoked during drilling CFRP(Wang et al., 2015).

The comprehensive discussion in this experiment has been taking place on the effects of machining parameters and the drill geometry types on the drilled holes quality. Grilo et al. (Grilo, Paulo, Silva, \& Davim, 2013) acquire examined using processed image analysis (SEM) to study the effects of cutting parameters for separate tercet drills on the delamination, assessed through two delamination factors. In an eager point, Davim and Reis (Davim \& Reis, 2003) have calculated by whole stratification way based on combining of Taguchi's model and on the analysis of variance (ANOVA) to base an interaction for both cutting velocity and feed rate with the delamination for drills types involving in a particular study of CFRP laminates. The similar method by Davim and Reis also presented by Tsao and HoCheng (Tsao \& Hocheng, 2004) in the contribution of cutting parameters and various drill bits on the thrust force. As the compelling result, high spindle speed along with low feed rates can be generated by a lower thrust force resulting in a reduction of delamination(Lin \& Chen, 1996). A comparison study of thrust force on drilling CFRP presented by Othman et al. (Othman, Hassan, Bakar, \& Othman, n.d.) using various drill types based on Taguchi's technique indicated the interaction between feed rate and spindle speed also the enormous influence of feed rate contributing to thrust force values. Machinability study, primarily for various penetration angle drilling process involving parameters results such as thrust force, hole morphology, hole quality, tool wear and machining temperature will affect the cutting process (Noorazizi, Izamshah, \& Kasim, 2017).

Numerous research has conducted on the CFRP drilling, but the performance of the twist, dagger and straight flute tools in the drilling of semi-finished aircraft composite panel notably including different of penetration angle is not conclusively presented elsewhere.Therefore, in this study, commercial tungsten carbide twist, dagger and straight flute drill bits will be used to drill the CFRP at $0^{\circ}, 15^{\circ}$ and $30^{\circ}$ penetration angle to mimic manual drilling and aimed to investigate drilling thrust force and observation on effect to the quality of drilled hole. The experiment will target on drilling of CFRP laminates for the use in the assembly of the leading-edge section for flap flat panel of commercial aircraft. Therefore the CFRP material for this section more high strength to support severe force and weather condition of commercial aviation plane.

\section{METHODOLOGY}

\section{Materials and Experimental Setup}

The specimen of CFRP composites laminate for experiment consists of 26 unidirectional plies of $0.125 \mathrm{~mm}$ thickness each, and top and bottom of laminates have each thin layers of glass/epoxy woven plies of 0.08 thickness to avoid delamination at the entrance and exit of drilling holes making the total laminate thickness $3.41 \mathrm{~mm}$. After the paint application, the final thickness of the composite panel involved in this experiment becomes $3.59 \mathrm{~mm}$. During the curing process, the CFRP were compacted using a vacuum pump in a controlled atmosphere and cured in autoclave until it achieved a nominal fibre volume fraction of $60 \%$. Experimental tests were conducted on a $15 \mathrm{~kW}$ DMU 40 mono BLOCK® CNC machine. The work piece was mounted on the adjustable vice with Kistler dynamometer which was fixed on the bed of the CNC drilling 
machine. A backing plate was used to support the laminate and clamp together with a set of clamping plate specially designated for this experiment which was firmly held in between the work piece and dynamometer to avoid any vibration effect. Figure 1 shows the experimental setup. The drilling trials were carried out using $6.35 \mathrm{~mm}$ diameter drill bits of three different types, as shown in Figure 2 and Table 3 shows the geometrical features for each drill types. Gandtrack Asia (Malaysia) Sdn Bhd manufactures all drills for this study. All drilling process was carried out in a dry condition without any coolant to prevent contamination between composite and coolant fluid. There also no pre-drilled hole was made in this experiment for thrust force measurement. Figure 3 shows the schematic diagram for penetration angle drilling.

Design of experiments has been implemented widely in engineering analysis. One of the designs is Taguchi design techniques that planned the experiment in a controlled way with the dedicated objective to execute the experiments. This experiment was conducted by Taguchi's method for four factors at three levels in consideration for the degree of the control factors observation, as shown in Table 1. Three different types of experiments which are for three types of drill bits conducted using Taguchi orthogonal array $\mathrm{L}_{9}\left(3^{4}\right)$. This method of Taguchi design more reliable and robust with dedicated to the number of trials with four columns at three levels which is related to four factors: drill types, drilling penetration angle $\left({ }^{\circ}\right)$, spindle rotation speed $(\mathrm{rpm})$ and feed rate (f) for machining. For each drilling process, three holes are drilled at $6.35 \mathrm{~mm}$ in diameter and results of thrust force values recorded using Kistler dynamometer type 5223A. The main concern of this experiment is to record the fluctuates of thrust force for the same drilling condition with various drills types. The output from dynamometer was processed by Dyno Ware software and visualised in the form of a graph for Z-axis of force. Next, the results of the experiment were analysed with the analysis of variance (ANOVA) using both software, Minitab 16 and Design Expert 10 to find the interaction and contribution percentage of machining parameters influence to dedicated factors set. The drilling holes qualities of CFRP panel were evaluated based on the defects after each drilling process. Consecutive holes were evaluate using Optical Microscope EZ-Meiji for drilled hole quality observation.

Table 1: Levels to the Drill Test Factors Assigned

\begin{tabular}{|l|c|c|c|c|}
\hline \multicolumn{1}{|c|}{ Level } & & $\mathbf{1}$ & $\mathbf{2}$ & $\mathbf{3}$ \\
\hline Drills Type & & Twist & Dagger & Straight flute \\
\hline Penetration Angle & $\left({ }^{\circ}\right)$ & 0 & 15 & 30 \\
\hline Feed Rate & $(\mathrm{mm} / \mathrm{rev})$ & 0.05 & 0.10 & 0.15 \\
\hline Spindle Speed & $(\mathrm{rpm})$ & 1000 & 2500 & 4000 \\
\hline
\end{tabular}

Table 2: Taguchi's Design Scheme of Experiments Orthogonal Array

\begin{tabular}{|c|l|c|c|c|}
\hline $\mathbf{L} \mathbf{9}\left(\mathbf{3}^{\mathbf{4}}\right)$ Test & Drill Types & Penetration Angle $\left(^{\circ}\right)$ & Feed Rate $(\mathbf{m m} / \mathbf{r e v})$ & Spindle Speed (rpm) \\
\hline $\mathbf{1}$ & Twist & 0 & 0.05 & 1000 \\
\hline $\mathbf{2}$ & Twist & 15 & 0.1 & 2500 \\
\hline $\mathbf{3}$ & Twist & 30 & 0.15 & 4000 \\
\hline $\mathbf{4}$ & Dagger & 0 & 0.1 & 4000 \\
\hline $\mathbf{5}$ & Dagger & 15 & 0.15 & 1000 \\
\hline $\mathbf{6}$ & Dagger & 30 & 0.05 & 2500 \\
\hline $\mathbf{7}$ & Straight Flute & 0 & 0.15 & 2500 \\
\hline $\mathbf{8}$ & Straight Flute & 15 & 0.05 & 4000 \\
\hline $\mathbf{9}$ & Straight Flute & 30 & 0.1 & 1000 \\
\hline
\end{tabular}




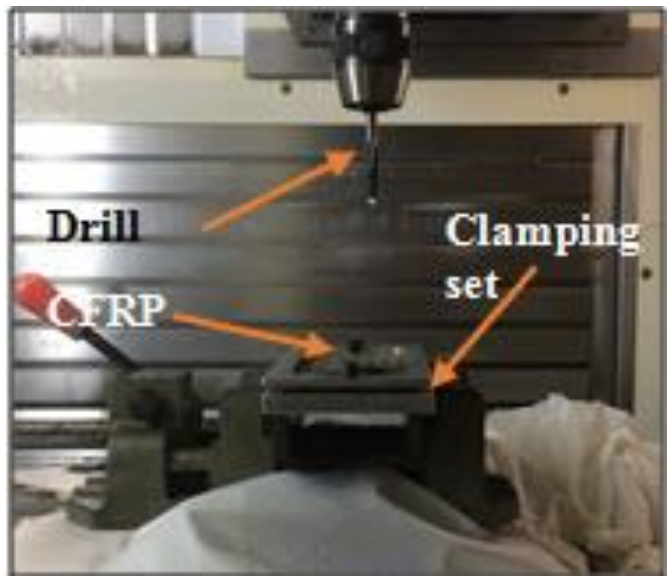

Figure 1: Clamping Set Upper and Beneath CFRP Laminates Panel to Prevent Vibration.

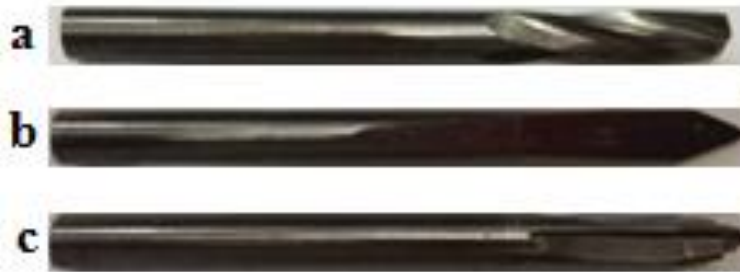

Figure 2: Drill Bits a) Twist Drill, b) Dagger Drill, c) Straight Flute Drill.

Table 3: Drill Bit Geometrical Features for a Designed Experiment

\begin{tabular}{|l|c|c|c|}
\hline \multicolumn{1}{|c|}{ Features } & Twist & Dagger & Straight Flute \\
\hline Point Angle $\left(^{\circ}\right)$ & 120 & 30 & 90 \\
\hline Helix Angle $\left({ }^{\circ}\right)$ & 11 & 0 & 0 \\
\hline Web Thickness $(\%)$ & 30 & - & 30 \\
\hline No. of Flutes & 4 & 2 & 4 \\
\hline No. of Cutting Edges & 2 & 2 & 4 \\
\hline
\end{tabular}

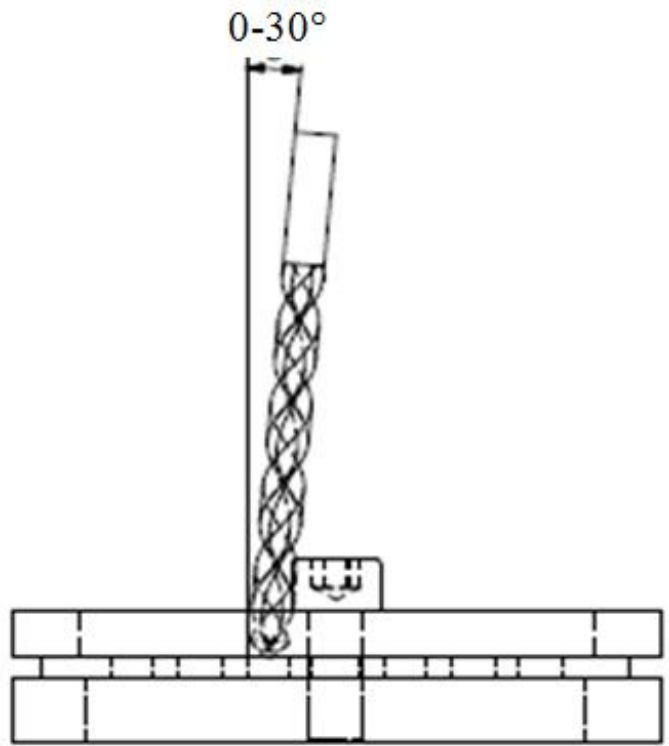

Figure 3: Penetration Angle Drilling $\left(0^{\circ}, 15^{\circ}\right.$ and $\left.30^{\circ}\right)$. 


\section{RESULTS AND DISCUSSION}

\section{Influence Variation of the Cutting Parameters in the Thrust Force for Various Drill Geometry Types}

Thrust force for drilling was measured using Kistler dynamometer type 5233A, and the thrust force values gained processed by Dyno Ware software. The results for an experimental test using Taguchi technique is shown in Table 4 . Cutting parameters such as drill types, feed rate and spindle speed has influenced thrust force on drilling CFRP. From the conducted experiment, the results of data variation from different drill types and cutting parameters observed. From the main effects plot for SN ratios from Minitab software in Figure 4, it shows that the penetration angle thus not contribute significant influence for thrust force as compared to the with drill types, feed rate and spindle speed. Based on the thrust force ANOVA results for each parameter show that p-value for drilling penetration angle more significant than 0.05 thus not significantly contribute towards the thrust force value compared to another parameter such as drill types, feed rate and spindle speed in this study. Dagger drill is the best drill type that contributes to the lowest thrust force compared with straight flute drill and twist drill. In this experiment, the low thrust force obtained with low feed rate $(0.05 \mathrm{~mm} / \mathrm{rev})$ and high spindle speed $(4000 \mathrm{rpm})$. This finding coincides with much previous research conducted on drilling composite materials (Allen et al., 2017; Ashrafi, 2015; N. Feito, Díaz-Álvarez, López-Puente, \& Miguelez, 2018; Liu, Tang, \& Cong, 2012; Shunmugesh \& Panneerselvam, 2017).

Table 4: Experimental Results

\begin{tabular}{|c|c|c|c|c|c|c|c|}
\hline & & & & & $\mapsto \stackrel{\oplus}{\oplus}$ & N $\stackrel{\stackrel{H}{0}}{\stackrel{\oplus}{\oplus}}$ & $\omega \stackrel{\leftrightarrow}{\stackrel{\oplus}{9}}$ \\
\hline 볼. & $\begin{array}{l}\text { Drill } \\
\text { Types }\end{array}$ & 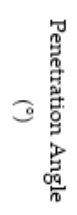 & 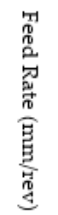 & 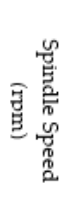 & 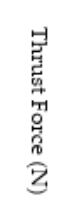 & 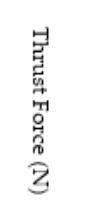 & 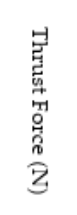 \\
\hline 1 & Twist & 0 & 0.05 & 1000 & 137.10 & 148.90 & 166.90 \\
\hline 2 & Twist & 15 & 0.10 & 2500 & 153.00 & 183.70 & 202.60 \\
\hline 3 & Twist & 30 & 0.15 & 4000 & 192.50 & 221.30 & 238.80 \\
\hline 4 & Dagger & 0 & 0.10 & 4000 & 113.50 & 115.00 & 115.20 \\
\hline 5 & Dagger & 15 & 0.15 & 1000 & 170.40 & 171.20 & 165.20 \\
\hline 6 & Dagger & 30 & 0.05 & 2500 & 77.91 & 80.30 & 81.43 \\
\hline 7 & $\begin{array}{l}\text { Straight } \\
\text { flute }\end{array}$ & 0 & 0.15 & 2500 & 159.63 & 176.80 & 185.80 \\
\hline 8 & $\begin{array}{l}\text { Straight } \\
\text { flute }\end{array}$ & 15 & 0.05 & 4000 & 83.01 & 91.53 & 99.88 \\
\hline 9 & $\begin{array}{l}\text { Straight } \\
\text { flute }\end{array}$ & 30 & 0.10 & 1000 & 149.60 & 163.20 & 172.10 \\
\hline
\end{tabular}




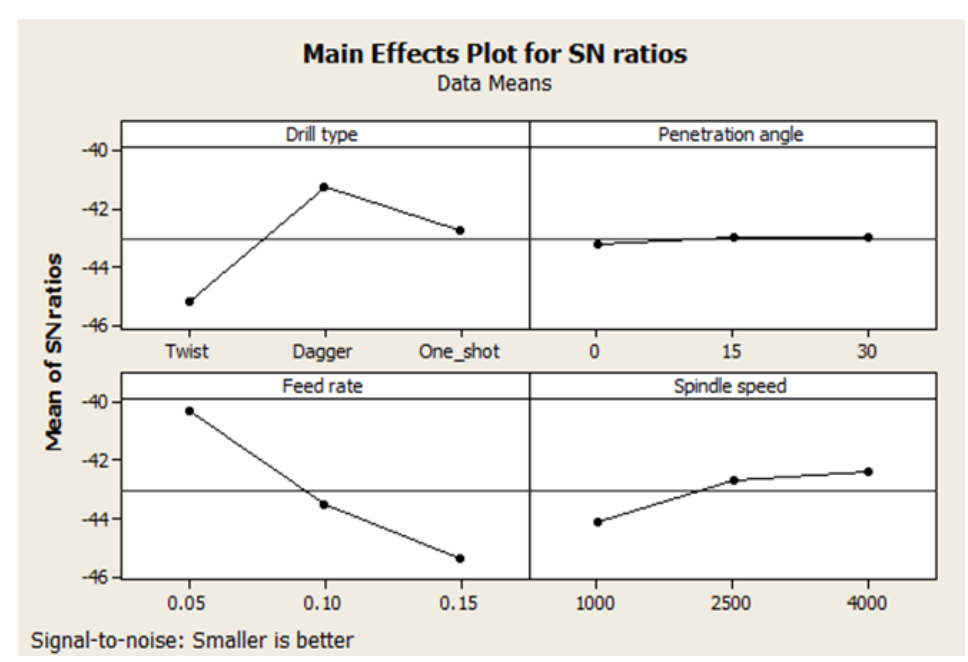

Figure 4: SN Ratios Effects of the Thrust Force.

\section{Analysis of Variance (ANOVA) for Maximum Thrust Force (FT MAX $_{\text {) }}$}

In this research works, the experimental results have been further analysed by analysis of variance (ANOVA) as summarised in Table 5. The ANOVA also signify the model posses the p-value is less than 0.05 , which means the polynomial equation that generated able to represent the actual experimental condition between cutting parameters and the thrust force. This is further proved by the lack of fit test, which indicates that the reduced linear model has insignificant $\mathrm{p}$ values. The "Lack of Fit F-value" of 0.49 implies the lack of fit is not significant to the pure error. There is a $61.78 \%$ chance that a "Lack of Fit F-value" this large could occur due to noise. Therefore, the model can be used to navigate the design space. The model F-value of 42.48 implies the model is significant and there only a $0.01 \%$ chance that a "Model Fvalue" this large could occur due to noise. According to Table 6, the developed model found to be the most suitable model with adjusted $\mathrm{R}^{2}$ and predicted $\mathrm{R}^{2}$ as much as 0.9054 and 0.8689 , respectively. The predicted $\mathrm{R}^{2}$ of 0.8689 is in reasonable agreement with the adjusted $\mathrm{R}^{2}$ of 0.9054 . This specifies that the model obtained will be able to give a reasonable estimate of the response of the system in the experimental range studied. Adequate precision was also found to be 19.676. "Adeq Precision" measures the signal to noise ratio. A ratio higher than four is considered to be desirable. Referred to ANOVA results in Table 5, the statistical significance of terms on thrust force are A, C and D, which the confidence level is less than 0.05 .

\begin{tabular}{|c|c|c|c|c|c|c|}
\hline \multicolumn{7}{|c|}{ Table 5: ANOVA for the Response of Reduced 2FI Model for Thrust Force } \\
\hline & Sum of & & Mean & $\mathbf{F}$ & p-value & \\
\hline Source & Squares & df & Square & Value & Prob > F & \\
\hline Model & 48118.50 & 6 & 8019.75 & 42.48 & $<0.0001$ & significant \\
\hline A-Drill type & 8034.62 & 2 & 4017.31 & 21.28 & $<0.0001$ & \\
\hline B-Angle Penetration & 188.89 & 1 & 188.89 & 1.00 & 0.3291 & \\
\hline C-Feed Rate & 28375.18 & \begin{tabular}{|l|}
1 \\
\end{tabular} & 28375.18 & 150.31 & $<0.0001$ & \\
\hline D-Spindle Speed & 1679.68 & 1 & 1679.68 & 8.90 & 0.0074 & \\
\hline $\mathrm{BC}$ & 236.38 & 11 & 236.38 & 1.25 & 0.2764 & \\
\hline Residual & 3775.64 & 20 & 188.78 & & & \\
\hline Lack of Fit & 196.72 & 2 & 98.36 & 0.49 & 0.6178 & not significant \\
\hline Pure Error & 3578.92 & 18 & 198.83 & & & \\
\hline Cor Total & 51894.15 & 26 & & & & \\
\hline
\end{tabular}


Table 6: R-Squared Analysis for Response Surface in Thrust Force

\begin{tabular}{|l|c|l|c|}
\hline Std. Dev. & 13.7398 & R-Squared & 0.927243 \\
\hline Mean & 148.7589 & Adj R-Squared & 0.905416 \\
\hline C.V. \% & 9.236289 & Pred R-Squared & 0.86886 \\
\hline
\end{tabular}

The prediction model of thrust force for twist drill, dagger drill and straight flute drill in this experiment can be denoted in Equation 1, 2 and 3.

\section{For Twist Drill}

Thrust Force $=116.20833+0.21596 *$ Angle Penetration $+794.07778 *$ Feed Rate $-6.44 \mathrm{x} 10-3 *$ Spindle Speed

\section{For Dagger Drill}

Thrust Force $=4.57944+0.21569 *$ Angle Penetration $+794.07778 *$ Feed Rate -6.44 x 10-3 $*$ Spindle Speed

\section{For Straight Flute Drill}

Thrust Force $=75.84722+0.21569 *$ Angle Penetration $+794.07778 *$ Feed Rate $-6.44 \times 10-3 *$ Spindle Speed

The above equation model can be used for values of the thrust force prediction within the factors in this study. In Figure 5, 3D response surface plots show the effect of cutting parameters on the thrust force at different drilling penetration angle and feed rate for twist drill, dagger drill and straight flute drill. The reflected graph denotes the thrust force with two different parameters and keeping the spindle speed parameter constant at the middle level, which is $1750 \mathrm{rpm}$. From the plotted graph, it can be stated as thrust force increases with an increased drilling penetration angle and decreasing penetration angle and feed rate will cause lower thrust force generated. Dagger drill showed the lowest thrust force effect from its sharp tip angle enables the tool to drill through the CFRPs plies acted as a pre-drilled hole at the initial drilling process.

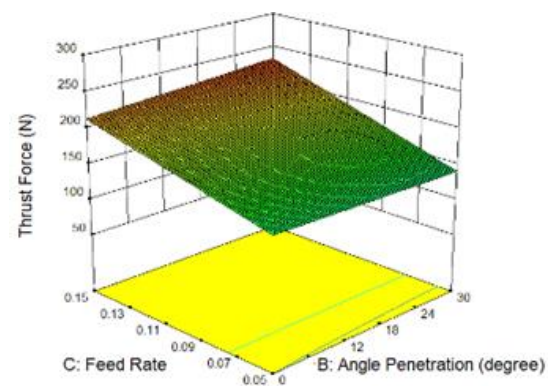

a) Twist drill

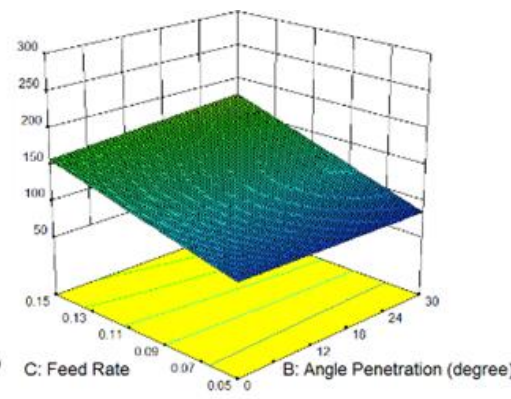

b) Dagger drill

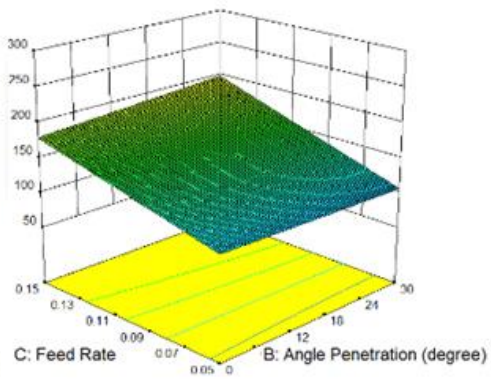

c) Straight flute drill

Figure 5: Response Surface Graph on Cutting Parameters vs Thrust Force.

\section{Drilled Hole Quality Observation}

Figure $6 \mathrm{a}$ until $6 \mathrm{c}$ shows the damage of in and out for drilling using twist drill, dagger drill and straight flute drill, respectively. The characteristic of damage differs effect from different drilling penetration implemented. The drilled holes' using the twist drill was found most severely damaged compared with others. Uncut fibre barely can be seen at hole number 5 and 7 when using twist drill. It found that the higher feed rate of machining using a twist drill can eliminate the uncut fibre damage. The most observed damage for this experiment is pushed out damage or exit delamination, which is visible when increasing the penetration angle. From the observation, the extent of the damages such as uncut fibres and 
exit delamination can be reduced when using twist drill rather than dagger drill and straight flute drill in $15^{\circ}$ and $30^{\circ}$ penetration angles.

For overall hole quality observation from drilling using this design of experiment found that the hole was achieved by straight flute drill were the best hole quality and twist drill was better than a dagger drill. Four flute cutters edges are producing better hole quality rather than two flute cutters edges due to its cutting edges. Basically, in one complete drill rotation, four cutting edges can cut four times for the same area compared with two cutting edges respectively. Therefore, dagger drill attained lower thrust force with small tip cutter cannot gain better hole quality compare with a twist and straight flute drill due to dagger drill only have 2 cutters edges per rotation compared with straight flute drill that has 4 cutters edges per rotation consequently influence hole quality level for both in and out of drilled holes.

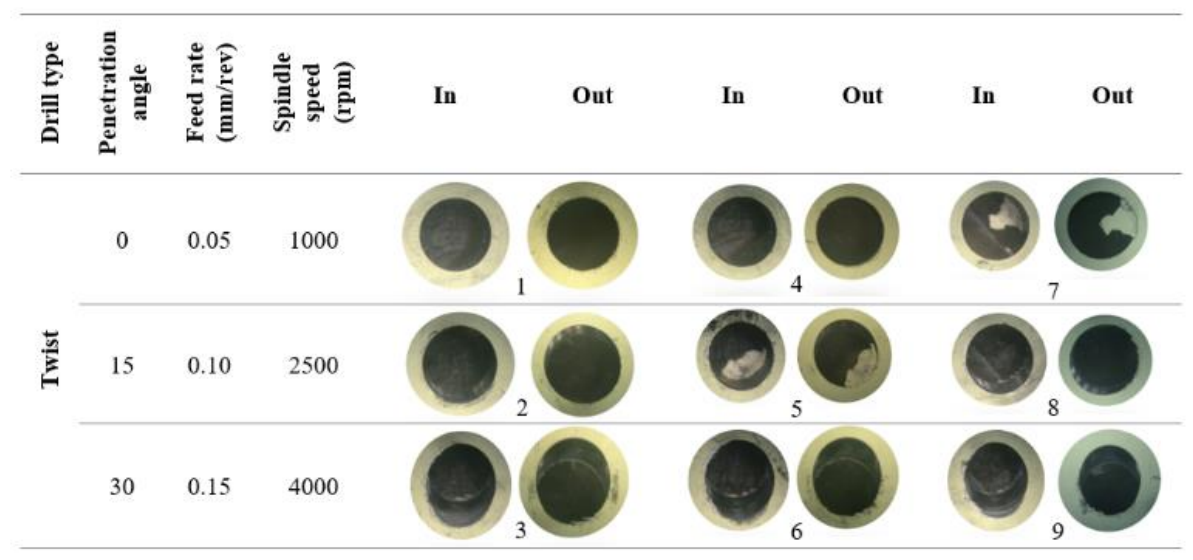

Figure 6a: Hole Quality Observation of $9^{\text {th }}$ Drilled Holes using a Twist Drill Based on Taguchi Design Plan.

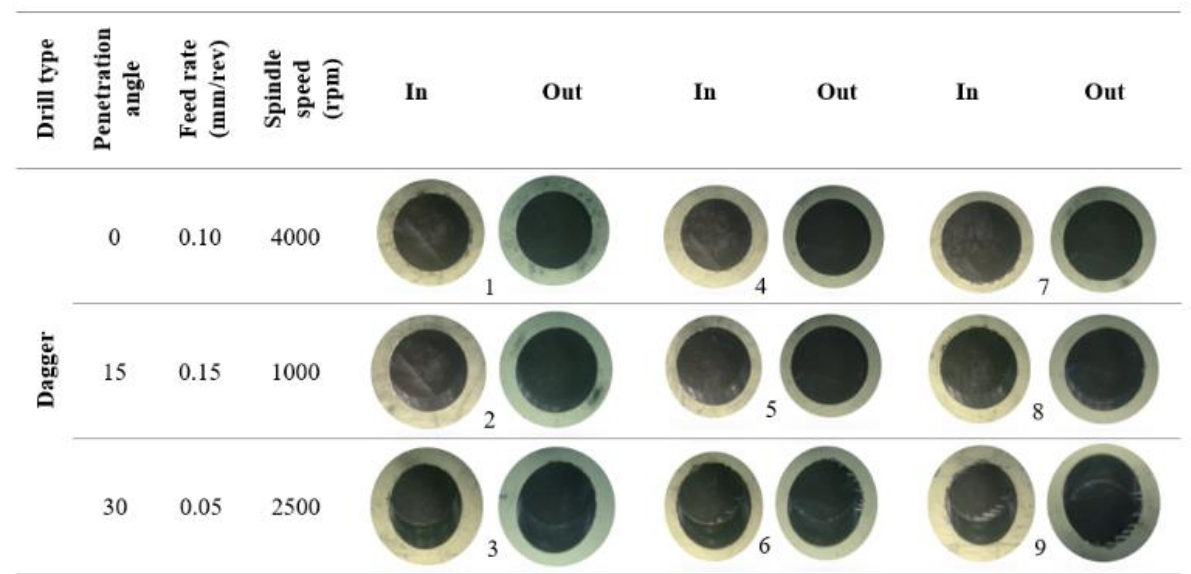

Figure 6b: Hole Quality Observation of $9^{\text {th }}$ Drilled Holes using a Dagger Drill Based on Taguchi Design Plan. 


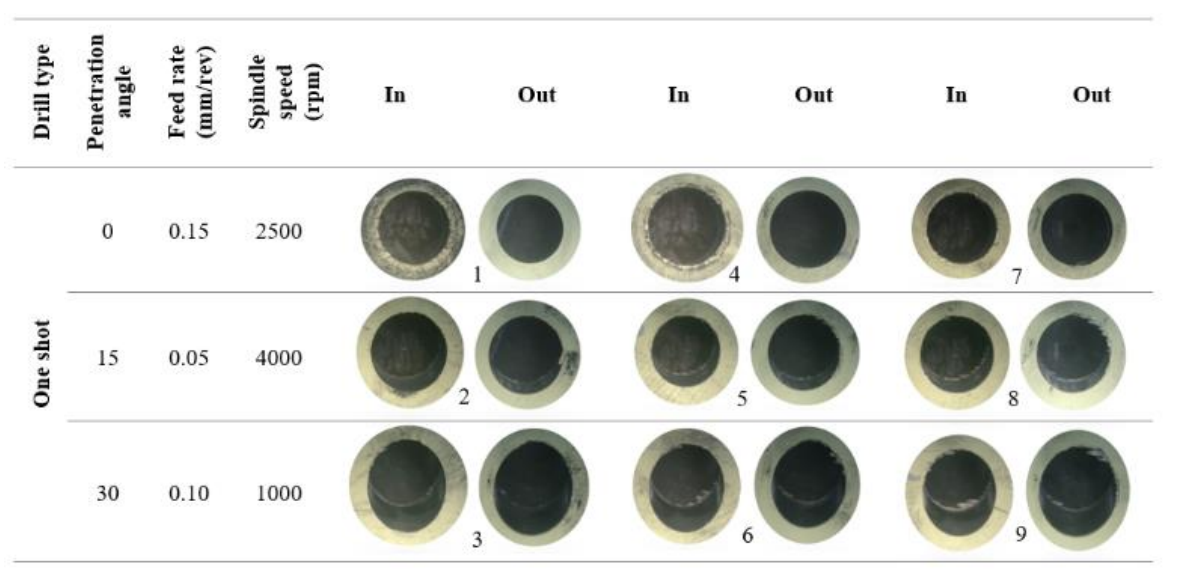

Figure 6c: Hole Quality Observation of 9th Drilled Holes using a Straight Flute Drill Based on Taguchi Design Plan.

\section{CONCLUSIONS}

From this study of drilling CFRP composite laminates using carbide twist drill, carbide dagger drill and carbide straight flute drill has been presented. The design of the experiment using Taguchi method and analysis of variance (ANOVA) to study the effect of cutting speed, feed rate and drilling penetration angle on the thrust force also hole quality observation the following conclusions can be drawn:

- Based on F-values in ANOVA results, feed rate parameter is contributing $72.64 \%$ statistical influence on thrust force during drilling in this experiment. Followed by drill type provided $22.58 \%$, spindle speed contributes $4.3 \%$ and less than $1 \%$ for penetration angle parameter.

- Twist drill, dagger drill and straight flute drill showed the same trend of characteristics that influence the thrust consistent spindle speed. The thrust force is decreasing when declining the feed rate and drilling penetration angle.

- Dagger drill contributes the smallest thrust force acquired compared with twist drill and straight flute drill. While straight flute drill contributes the best hole quality based on observation at entry and exit of drilled holes.

- Despite drilling penetration angle not so influence the thrust force parameter, its effect overall hole quality especially on $15^{\circ}$ and $30^{\circ}$ penetration angle that causes delamination such as uncut fibre at the exit side of the drilling for all drill types.

\section{ACKNOWLEDGEMENTS}

The author would like to thank the Universiti Teknikal Malaysia Melaka (UTeM) and the Ministry of Education Malaysia for financial support receive under research grant FRGS/2018/FKP-AMC/F00379 and Hadiah Latihan Persekutuan scholarship.

\section{REFERENCES}

1. Allen, J., Ramirez, C., Poulachon, G., Rossi, F., M'Saoubi, R., Caggiano, A., Bremen, M. P. (2017). A Review Paper on Effects of Drilling on Glass Fiber Reinforced Plastic. Composite Structures, 9(2), 1-10. https://doi.org/10.1063/1.5008116.

2. Ashrafi, S. A. (2015). Effect of Tool Geometry on Cutting Mechanism and Hole Quality when Drilling Carbon Fiber Reinforced (CFRP) Composites, (May). Retrieved from https://books.google.com/books?id=ZFRIAQAACAAJ. 
3. Breuer, U. P. (2016). Commercial aircraft composite technology. Commercial Aircraft Composite Technology. https://doi.org/10.1007/978-3-319-31918-6.

4. Brinksmeier, E., Fangmann, S., \& Rentsch, R. (2011). Drilling of composites and resulting surface integrity. CIRP Annals Manufacturing Technology, 60(1), 57-60. https://doi.org/10.1016/j.cirp.2011.03.077.

5. Caggiano, A., Angelone, R., \& Teti, R. (2017). Image Analysis for CFRP Drilled Hole Quality Assessment. Procedia CIRP, 62, 440-445. https://doi.org/10.1016/j.procir.2017.03.045.

6. Chawla, K. K. (2013). Composite Materials.

7. Chung, D. D. L. (1994). Carbon Fiber Composites. Carbon.

8. Davim, J. P., \& Reis, P. (2003). Drilling carbon fiber reinforced plastics manufactured by autoclave-experimental and statistical study. Materials and Design, 24(5), 315-324. https://doi.org/10.1016/S0261-3069(03)00062-1

9. Eneyew, E. D., \& Ramulu, M. (2014). Experimental study of surface quality and damage when drilling unidirectional CFRP composites. Journal of Materials Research and Technology, 3(4), 354-362. https://doi.org/10.1016/j.jmrt.2014.10.003

10. Feito, N., Diaz-Álvarez, A., Cantero, J. L., Rodríguez-Millán, M., \& Miguélez, H. (2016). Experimental analysis of special tool geometries when drilling woven and multidirectional CFRPs. Journal of Reinforced Plastics and Composites. https://doi.org/10.1177/0731684415612931

11. Feito, N., Díaz-Álvarez, J., López-Puente, J., \& Miguelez, M. H. (2018). Experimental and numerical analysis of step drill bit performance when drilling woven CFRPs. Composite Structures, 184(August 2017), 1147-1155. https://doi.org/10.1016/j.compstruct.2017.10.061

12. Grilo, T. J., Paulo, R. M. F., Silva, C. R. M., \& Davim, J. P. (2013). Experimental delamination analyses of CFRPs using different drill geometries. Composites Part $\quad B: \quad$ Engineering, $45(1), \quad 1344-1350$. https://doi.org/10.1016/j.compositesb.2012.07.057

13. Hafiz, M. S. A., Kawaz, M. H. A., Mohamad, W. N. F., Kasim, M. S., Izamshah, R., Saedon, J. B., \& Mohamed, S. B. (2017). A review on feasibility study of ultrasonic assisted machining on aircraft component manufacturing. IOP Conference Series: Materials Science and Engineering, 270(1). https://doi.org/10.1088/1757-899X/270/1/012034

14. Lin, S. C., \& Chen, I. K. (1996). Drilling carbon fiber-reinforced composite material at high speed. Wear, 194(1-2), 156-162. https://doi.org/10.1016/0043-1648(95)06831-7

15. Liu, D. F., Tang, Y. J., \& Cong, W. L. (2012). A review of mechanical drilling for composite laminates. Composite Structures, 94(4), 1265-1279. https://doi.org/10.1016/j.compstruct.2011.11.024

16. Montoya, M., Calamaz, M., Gehin, D., \& Girot, F. (2013). Evaluation of the performance of coated and uncoated carbide tools in drilling thick CFRP/aluminium alloy stacks. International Journal of Advanced Manufacturing Technology, 68(9-12), 2111-2120. https://doi.org/10.1007/s00170-013-4817-0

17. Noorazizi, M. S., Izamshah, R., \& Kasim, M. S. (2017). Effects of Drill Geometry and Penetration Angle on Temperature and Holes Surfaces for Cortical Bovine Bone: An in Vitro Study. Procedia Engineering, 184, 70-77. https://doi.org/10.1016/j.proeng.2017.04.072

18. Othman, A. R., Hassan, M. H., Bakar, E. A., \& Othman, W. A. F. W. (n.d.). Statistical Analysis of the Machining Parameters in Drilling of Carbon Fibre Reinforced Plastics (CFRP) Composite with Various Drill Types. Springer Singapore. https://doi.org/10.1007/978-981-10-8788-2 
19. Shunmugesh, K., \& Panneerselvam, K. (2017). Optimization of drilling process parameters Via Taguchi, TOPSIS and RSA techniques. Archives of Metallurgy and Materials, 62(3), 1803-1812. https://doi.org/10.1515/amm-2017-0273

20. Soutis, C. (2005). Fibre reinforced composites in aircraft construction. Progress in Aerospace Sciences, 41(2), $143-151$. https://doi.org/10.1016/j.paerosci.2005.02.004

21. Tsao, C. C., \& Hocheng, H. (2004). Taguchi analysis of delamination associated with various drill bits in drilling of composite material. International Journal of Machine Tools and Manufacture, 44(10), 1085-1090. https://doi.org/10.1016/j.ijmachtools.2004.02.019

22. Wang, C. Y., Chen, Y. H., An, Q. L., Cai, X. J., Ming, W. W., \& Chen, M. (2015). Drilling temperature and hole quality in drilling of CFRP/aluminum stacks using diamond coated drill. International Journal of Precision Engineering and Manufacturing, 16(8), 1689-1697. https://doi.org/10.1007/s12541-015-0222-y

23. Zweben, C. (1981). Advanced composites for Aerospace applications. Composites, 12(October), $235-240$. https://doi.org/10.1016/0010-4361(81)90011-2

24. Jweeg, Muhsin J., Abdul-Kareem F. Hasan, and Jawad K. Zeboon. "Investigation of Impact Response for CFRP/Steel Hybrid Composite Plate Under Low-Velocity Impact." International Journal of General Engineering and Technology (IJGET) 3.2 (2014):1-10

25. Suman, Swapnil, et al. "Experimental investigation on influence of functionalized multi-walled carbon nanotubes on surface roughness in drilling of CFRP composites." International Journal of Mechanical and Production Engineering Research and Development (IJMPERD) 8.3 (2018): 1133-1146.

26. Suman, Swapnil, et al. "Influence of functionalized multi-walled carbon nanotubes On the mechanical properties and delamination in drilling of CFRP composites." International Journal of Mechanical and Production Engineering Research and Development (IJMPERD), 8.3 (2018): 1067-1084.

27. Nduka, Asanya Onyebuchi. "Innovation in a Water Well Potable Drilling Machine Design Analysis." BEST: International Journal of Management Information Technology and Engineering (BEST: IJMITE) 8.1 (2020):1-10.

28. Venkatesh, Bellam, and Rahul Singh Sikarwar. "Drilling of Carbon Fibre Reinforced Polymer Materials-A Review." International Journal of Mechanical and Production Engineering Research and Development (IJMPERD) 8.2 (2018): 157-166. 

